In course of a screening consultation 736 patients have been screened to date. The patients have to wait in average about 42 days from the suspected diagnosis to the rejected or confirmed rheumatological diagnosis.

Conclusion: Although the average waiting time for all three diseases is currently almost twice as long as the 23.9 days in the Rhineland-Palatinate predecessor project ADAPTHERA which just focuses on RA, the current results are very positive compared to the national average [3]. The aim is to further increase the screening quality and screening numbers, especially in the 1-year follow-up. Current data will be presented at the conference.

References:

[1] Boehncke WH, Menter A (2013) Burden of disease: psoriasis and psoriatic arthritis. Am J Clin Dermatol 14:377-388

[2] Claudepierre P (2014) Spondyloarthritis: a window of opportunity? Joint Bone Spine 81:197-199

[3] Lauter A, Triantafyllias K, Leiß R et al. (2019) ADAPTHERA-Statewide cross-sectoral care network for patients with early rheumatoid arthritis shows sustained remission in standard care. ZRheumatol. 78 (7): 660-669

[4] O'dell JR (2002) Treating rheumatoid arthritis early: a window of opportunity? Arthritis Rheum 46:283-285

[5] Schwarting A (2018) From ADAPTHERA to Rheuma-VOR: Concept of Coordinated Cooperation to Improve the Quality of Rheumatology Care Akt Rheumatol 43 (05): 406-409

Acknowledgments: The authors thank all partners and participants of Rheuma-VOR

Disclosure of Interests: Matthias Dreher: None declared, Reinhold E. Schmidt: None declared, Torsten Witte: None declared, Gunter Assmann: None declared, Kirsten Hoeper Consultant of: AbbVie, Celgene,, Speakers bureau: Abbvie, Chugai, Novartis, Lilly, Celgene, Sandoz Hexal, Konstantinos Triantafyllias: None declared, Jan Zeidler: None declared, Harald Binder: None declared, Andreas Schwarting: None declared

DOI: 10.1136/annrheumdis-2020-eular.5559

\section{AB1299-HPR THE RHEUMA-VOR APP: OPTIMIZING THE EARLY DIAGNOSIS OF RHEUMATIC DISEASES}

M. Dreher ${ }^{1}$, L. Wojnowski ${ }^{2}$, D. Tibyampansha ${ }^{2}$, A. Hilt $^{3}$, A. Schwarting ${ }^{1,3}$. ${ }^{1}$ University Medical Center of the Johannes Gutenberg University Mainz, Division of Rheumatology and Clinical Immunology, Mainz, Germany; ${ }^{2}$ University Medical Center of the Johannes Gutenberg University Mainz, Department of Pharmacology, Mainz, Germany; ${ }^{3}$ ACURA Center of Rheumatology Rhineland-Palatinate, Bad Kreuznach, Germany

Background: The proof-of-concept network study "Rheuma-VOR" aims to improve the quality of rheumatological care through coordinated cooperation. In particular, rheumatic diseases should be diagnosed as early as possible and treated quickly in a targeted manner [3]. Smartphone apps have a potential to improve the management of chronic diseases. For example, they can be used to provide health information, or to offer self-monitoring and self-screening options [1, 2]

Objectives: The Rheuma-VOR Screening-App study examines whether a smartphone-based app can increase the detection rate of the three most common chronic inflammatory rheumatic diseases: rheumatoid arthritis, psoriatic arthritis and spondylarthritis.

Methods: Based on the multi-stage Delphi Procedure, a minimal list of questions for detection and differentiation between the three diseases was defined. The app for iOS and Android is in use since October 2018 during the screening consultation at the Division of Rheumatology and Clinical Immunology and the ACURA Center of Rheumatology Rhineland-Palatinate. An additional validation will be performend with a non-preselected cohort based on the data of the Rheuma Bus Tour 2019.

Results: The Delphi Procedure identified 17 questions, including four laboratory parameters. They have been deployed in German as a smartphone app. The questions are read to the patient and can be answered with "YES", "NO", or "I DO NOT KNOW". Answering the questions takes approximately four minutes. The suspected diagnoses are based on a cumulative score. Some diagnoses are excluded or confirmed already after a few questions.

To date (31 Dec 2019), the app has been used on 466 patients. The sensitivity is 0.91 , while the specificity is 0.25 . The positive predictive value and the negative predictive values are 0.60 and 0.32 , respectively. The false positive value is 0.33 and the false negative value 0.05 .

Conclusion: The Rheuma-VOR App helps doctors and patients to invalidate or to confirm the suspicion of a possible rheumatic disease. Data from the cohort is currently analyzed to increase the screen's specificity. The additional validation, based on a non-preselected cohort collected during the Rheuma Bus Tour 2019, is in progress. A final validation concept is currently being developed.
In 2020, a section with the most important information about the aforementioned three diseases will be added. The section will include definition, etiology, prognosis, symptoms, therapeutic principles, medication and case studies.

Current data will be presented at the conference

\section{References:}

[1] Kuijpers W, Groen WG, Aaronson NK et al. (2013) A systematic review of web-based interventions for patient empowerment and physical activity in chronic diseases: relevance for cancer survivors. Journal of medical Internet research 15:e37

[2] Payne HE, Lister C, West JH et al. (2015) Behavioral functionality of mobile apps in health interventions: a systematic review of the literature. JMIR mHealth and uHealth 3:e20

[3] Schwarting A (2018) From ADAPTHERA to Rheuma-VOR: Concept of Coordinated Cooperation to Improve the Quality of Rheumatology Care Akt Rheumatol 43 (05): 406-409

Acknowledgments: The authors thank all partners and participants of Rheuma-VOR

Disclosure of Interests: None declared

DOI: 10.1136/annrheumdis-2020-eular.5646

\section{AB1300-HPR MALNUTRITION SCREENING AND ASSESSMENT TOOLS IN RHEUMATIC DISEASES}

C. M. Gamboa-Alonso ${ }^{1}$, J. D. Ángulo ${ }^{1}$, R. E. Díaz-García ${ }^{1}$, G. Figueroa-Parra ${ }^{1}$, D. Á. Galarza-Delgado ${ }^{1}$, J. C. Riegatorres ${ }^{1} .{ }^{1}$ Hospital Universitario José Eleuterio González., Monterrey, Mexico

Background: Inflammatory disorders have been associated with an increased risk of malnutrition, defined as an abnormal physiologic condition caused by an insufficient, unbalanced or excessive intake of nutrients due to exacerbated metabolic states. ${ }^{1}$

Mini Nutritional Assessment (MNA) and Nutritional Risk Screening Tool 2002 (NRS-2002) have been used to evaluate nutritional status in patients with rheumatic diseases.

Objectives: Compare MNA and NRS-2002 as tools for nutritional screening in rheumatic patients.

Methods: 152 patients with rheumatic diseases were evaluated in a Rheumatology center of México. Anthropometrical measurements were performed using Bioelectrical Impedance Analysis (BIA) TANITA. MNA and NRS-2002 were applied at the same date.

MNA is comprised of a dietary questionnaire, subjective and objective global assessment and anthropometrical measurements, classified as adequate (MNA 24-30), risk for malnutrition (MNA 17-23.5) and malnutrition (MNA<17).

NRS-2002 consists of nutritional and severity disease score and an age adjustment for patients $>70$ years $(+1)$; classified as normal $(0-3)$ and risk of malnutrition/established malnutrition (3 or more).

For statistical analysis the SPSS v24 was used. A p $<0.05$ was considered statistically significant.

Results: A total of 152 patients with different rheumatic diseases were included Table 1. The results according to each tool are represented in Graphic 1. A significant difference was found by the Chi-Square-test when comparing both tools $(p<0.004)$.

Table 1. Socio-demographic characteristics of rheumatic patients

\section{DISEASES, $n(\%)$}

Rheumatoid Arthritis

Systemic Lupus Erythematosus

Ostearthrosis

Sjögren's Syndrome

Fibromyalgia

Ankylosing Spondylitis

Systemic Sclerosis

Others

SOCIO-DEMOGRAPHICS

Age, mean years $(S D)$

$B M I$, mean (SD)

Brachial Circumference, $\mathrm{cm}$, (SD)

Calf Circumference, $\mathrm{cm},(S D)$

A subanalysis in 70 Rheumatoid Arthritis patients was done with a mean age of 50.94 years $(S D \pm 12.11)$ and a mean $B M I 28.53 \mathrm{~kg} / \mathrm{m} 2$ (SD 5.48). The results according to each tool are represented in Table 2. When NRS-2002 was reclassified in 3 parameters (normal $<2$, risk of malnutrition 2 and malnutrition 3 or more), a significant difference persisted (p. 05) with a low correlation (.43). 